\title{
Experimental study on utilization of heat pipe heat exchanger for improving efficiency of clean room air system in hospitals
}

\author{
Imansyah Ibnu Hakim ${ }^{1 *}$, Nandy Putra $^{1}$, Adam Prihananda Marda ${ }^{1}$, Muhammad Alvin Alvaro ${ }^{1}$, and Adi Winarta ${ }^{1}$ \\ ${ }^{1}$ Heat Transfer Laboratory, Department of Mechanical Engineering, University of Indonesia, Kampus UI, Depok 16424, Indonesia
}

\begin{abstract}
Heating, Ventilation, and Air Conditioning (HVAC) system in hospital's clean room is required to continue working for 24 hours to provide the ideal air quality for the activities therein. This causes a huge amount of energy consumption in hospital buildings itself. This study aims to determine the effectiveness and heat recovery of Heat Pipe Heat Exchanger (HPHE). The HPHE used in this study consisted of 12 heat pipes per module, in which the line was arranged staggered. The number of the module is varied 3 times, which are 1, 2, and 3 modules. The heat pipe is made of copper and contains working fluid in the form of water with $50 \%$ filling ratio. HPHE equipped with fins to expand the contact surface with airflow. Each variation of the number of modules is tested on the HVAC system model of the clean room. In the evaporator inlet, air flowing to the variation of temperature: $28,30,35$, and $40{ }^{\circ} \mathrm{C}$, and at speeds of $1.5,2.0,2.5 \mathrm{~m} / \mathrm{s}$. The use of HPHE can recover heat as much as $1654.72 \mathrm{~kJ} / \mathrm{h}$. The highest effectiveness of this HPHE is $48.729 \%$, was obtained when using three modules, air temperature inlet evaporator $(\mathrm{Te}, \mathrm{i})=35^{\circ} \mathrm{C}$, and airspeed of inlet $1.5 \mathrm{~m} / \mathrm{s}$.
\end{abstract}

\section{Introduction}

Hospitals are health service institutions that provide a full range of personal health services (promotive, preventive, curative and rehabilitative), and provide inpatient, outpatient, and emergency care services [1]. Due to the many functions of the hospital, there are room types according to its function. The existing rooms in the hospital include the inpatient room, emergency room, laboratory room, pharmacy room, isolation room, and operating room.

Facilities and infrastructure in the hospital have an important role for the hospital to keep performing its functions. These facilities and infrastructure include buildings, air systems, mechanical and electrical systems, and medical equipment. The air-conditioning system for the clean room should continue to operate for 24 hours in order to keep functioning properly. Hospital rooms such as operating rooms, for example, have special specifications set in international standards.

The operating room has certain specifications regarding the value of temperature, relative humidity, and air change within it. Under the ASHRAE standard [2], the temperature inside the operating room should be in the range $20-24{ }^{\circ} \mathrm{C}$, the relative humidity of air at $30-60 \%$, and the change of air within it by 15-20 times per hour. The Heating Ventilation \& Air Conditioning (HVAC) system in the operating room is required to continue working for 24 hours to provide this specification. The use of this continuous HVAC system results in the enormous energy demand in hospitals. Energy Consumption Index for hospitals by the Indonesian National Standard (SNI) $05-3052-1992$ is $380 \mathrm{kWh} / \mathrm{m}^{2}$. Based on the results of the survey and energy audit conducted by BPPT and JICA on buildings in Jakarta, the intensity of energy use in buildings the hospital reached $239 \mathrm{kWh} / \mathrm{m}^{2}$ per year [3]. The HVAC system is the largest energy consumption in hospitals with a percentage of up to $60 \%$.

Because of this, a method is needed to reduce the energy consumption in HVAC in the hospital's clean room. One method is to use heat pipes as a heat recovery system. Heat Pipe Heat Exchangers (HPHE) have great potential for commercial and industrial applications, particularly in the HVAC [4]. This heat exchanger system virtually does not have cross-leakage between hot and cold airflow. Another advantage is that HPHE systems do not require input power to operate, are compact and passive, economical, reliable, have few components, and the design can be adjusted as needed [4].

Research on the use of heat pipe as heat recovery has been done. One of them is Putra et al [5] conducting an experimental study to investigate the thermal performance of heat pipes in the heat recovery of the operating room air conditioning system. HPHE consists of several tubular heat pipes with water as the working fluid and arranged staggered to 6 lines. Experiments were conducted to determine the effect of incoming air temperature, the number of lines used, and also the air velocity of entry. Experimental results suggested that the greater the air temperature, the greater the effectiveness of HPHE. It was found that with a decrease in air temperature coming into the evaporator of $2.4{ }^{\circ} \mathrm{C}$, its effectiveness value is 0.15 . This result was obtained when using 6 HPHE lines, $1 \mathrm{~m} / \mathrm{s}$ air velocity, and air intake temperature of evaporator 45 ${ }^{\circ} \mathrm{C}$. When air velocity doubled to $2 \mathrm{~m} / \mathrm{s}$, the system

Corresponding author: imansyah@eng.ui.ac.id 
achieved the greatest heat recovery value of 1404.29 $\mathrm{kJ} /$ hour

YH Yau [6] simulated the use of a double heat pipe heat exchanger in the operating room in order to decrease energy consumption. The model of an empirical transient system simulation program was made to estimate the energy consumption of the operating room per year. There are two systems compared to the simulation, HVAC system without HPHE and HVAC system with 8 HPHE lines. The results of his research stated that the use of HPHE is highly recommended as an effective tool in controlling moisture and as an energy saver to keep the condition of the room according to the standard specification.

Heat pipe heat exchangers used in air conditioning systems (AC) as secondary heat recovery are also examined by Haito Wang et al [7]. This study also compared two systems, but with different configurations. The first system used two HPHEs by laying before and after cooling coil, while the second system uses only one HPHE which is placed after the cooling coil. Experimental analysis showed that the average heat recovery efficiency of the system in winter is $21.08 \%$, while in summer it is $39.2 \%$. The results also showed that the use of two HPHEs was more effective.

Govinda Mahajan et al [8] conducted a study on the use of oscillating heat pipe (OHP) as heat recovery in HVAC systems. The goal is to utilize thermal energy wasted to pre-heat or pre-cool the air as a step to reduce the load on the HVAC system. OHP can have effective thermal conductivity up to $10000 \mathrm{~W} / \mathrm{m}-\mathrm{K}$ without wick structure. The results show that the full OHP can work in the air to air convection mode for heat recovery under typical HVAC system operating conditions.

From the description of the above research, it can be concluded that the use of the heat pipe heat exchanger is very important in order to save energy. Specifically, in the HVAC system of the clean room at the hospital, the use of heat recovery has the potential to reduce the energy consumption used. Therefore, further development of the use of HPHE on a clean room HVAC system needs to be done to find a more effective and efficient HPHE system.

In order to improve the effectiveness of HPHE, this research is conducted. The HPHE used in this study consisted of 12 heat pipes per module, in which heat pipe was arranged staggered. The used of 12 heat pipes aims to keep this device lightweight and easy to install. Staggered arrangement is used because more contact area between heat pipes and air, rather than inline arrangement. The number of modules is varied 3 times, 1, 2, and 3 modules. HPHE equipped with the fin to expand the contact surface with airflow. Each of these module configurations is tested on a clean room HVAC system model. In the evaporator inlet air flowing to the variation of temperature: $28,30,35,40{ }^{\circ} \mathrm{C}$, and at speeds of $1.5,2.0$, $2.5 \mathrm{~m} / \mathrm{s}$. In this study, the ducting schematic design was manufactured following the standard (ASHRAE) of clean room at the hospital using two outlets on the right and left side of the room simulator. Moreover, the refrigeration for the ducting system using mini water-cooled chiller system. This system is widely used in the actual application. The purpose of this study was to obtain the effectiveness and heat recovery of HPHE applications in clean room.

\section{Methodology}

\subsection{Heat Pipe Heat Exchanger Design}

In this study, a module of the heat pipe heat exchanger is equipped with tubular heat pipes in a staggered arrangement. Each module consists of 12 heat pipes. Heat pipe was made of copper with a length of $720 \mathrm{~mm}$ and an outer diameter of $10 \mathrm{~mm}$, the working fluid is water with a $50 \%$ filling ratio. Adiabatic area length is $380 \mathrm{~mm}$, length of an evaporator is $150 \mathrm{~mm}$ and condenser is 190 $\mathrm{mm}$ each. The HPHE evaporator is placed in fresh-supply air ducting, while the HPHE condenser is placed in returnexhaust air ducting.

Wavy fin material is aluminum with thickness 0.105 $\mathrm{mm}$. The length of the wavy fin is $100 \mathrm{~mm}$ and the width is $63.3 \mathrm{~mm}$. There are 90 wavy fins mounted on the evaporator and 95 mounted on the condenser. The distance between the wavy fins is $2 \mathrm{~mm}$. Fig. 1. shows the heat pipe heat exchanger design described above.

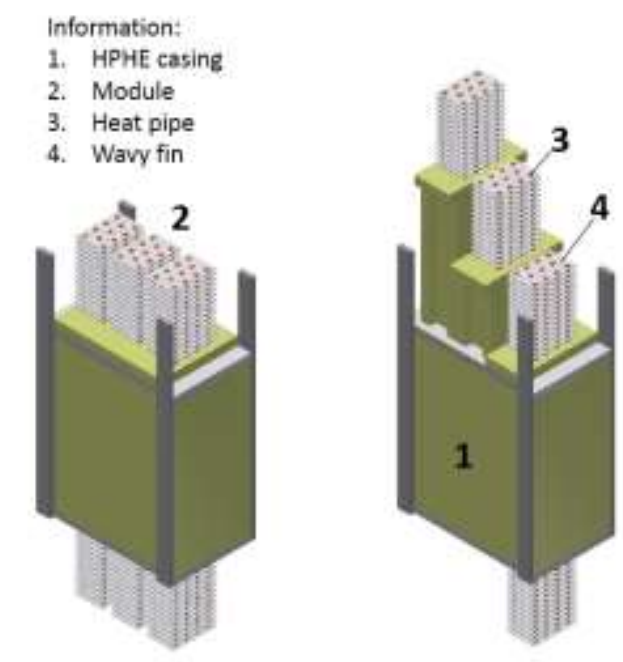

Fig. 1. Heat pipe heat exchanger design

\subsection{Experimental Ducting System}

Fig. 2. and Fig. 3. show the experimental ducting system used in this experiment. The experimental ducting system consist of:

- In the ducting of fresh-supply air: a 6000 Watts of heating element with PID controller; axial fan inlet; 2 temperature sensors; 2 relative humidity sensors; and a cooling coil.

- In the ducting return-exhaust air: axial fan outlet; 2 temperature sensors; 2 relative humidity sensors.

- Other components: The chamber; water container for cooling coil's refrigerant, air conditioner.

- Water cooling system (CTB): The water cooling system uses a $200 \mathrm{~m}^{3}$ water reservoir to contain the water that will flow into a tube connecting to the 
cooling coil unit. The water acts as a refrigerant in this system. Flowmeter is used to adjust water flowrate into the cooling coil.

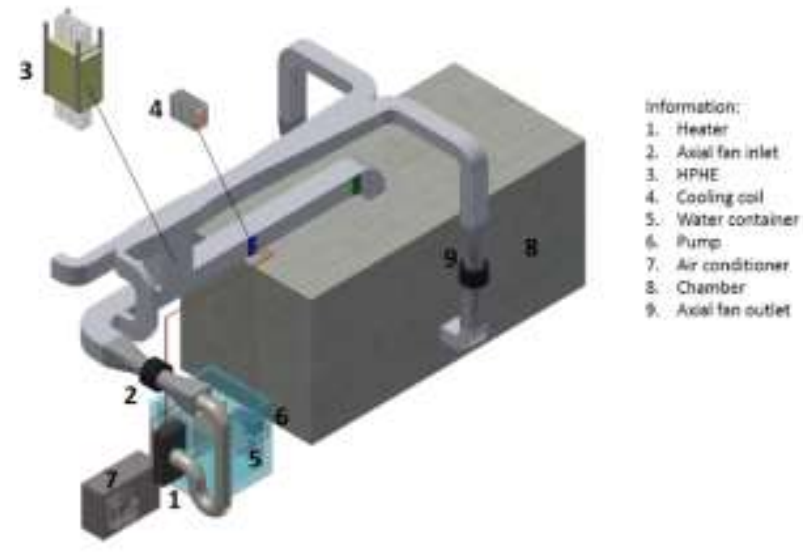

Fig. 2. Experimental ducting system design

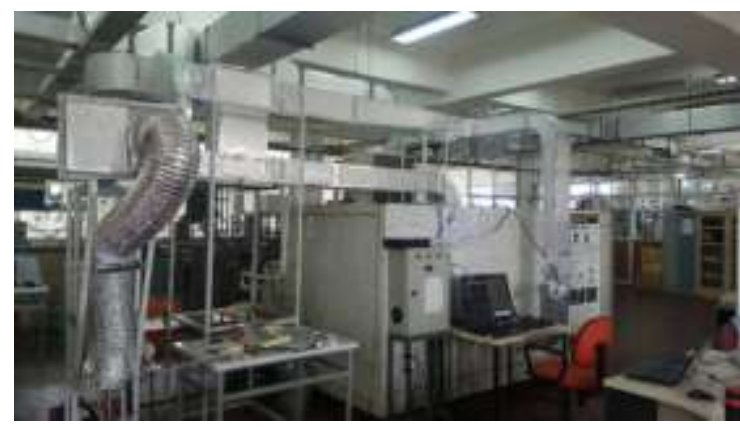

Fig. 3. Experimental rig at the laboratory

\subsection{Experimental Setup}

Fig. 4. shows a schematic of the tests performed in this study. The HPHE testing scheme consists of the components of the test equipment (HPHE and ducting system) and measuring instruments described in the preceding sections. The working process of this experimental begins by turning on the axial inlet fan to drain air into the HVAC system. Air velocities are adjusted according to the size determined as part of the independent variables, $1.5,2.0$, and $2.5 \mathrm{~m} / \mathrm{s}$. Before the air flows into the inlet ducting, the heating element with the PID controller adjusts the air intake in accordance with predetermined suggestions of $28,30,35,40{ }^{\circ} \mathrm{C}$, respectively. Then the air flows into the ducting and passes through the HPHE evaporator. The number of HPHE modules used varies to 1, 2, and 3 modules. After that air flows through the cooling coil with a $7{ }^{\circ} \mathrm{C}$ water refrigerant, and finally into the chamber. The air inside the chamber is sucked by the axial fan's outlet so it flows into the ducting outlet. The speed of the air flow in the ducting outlet is set equal to the speed at the inlet ducting. Cold air from this chamber passes through HPHE condenser for heat recovery. The performance of the HPHE in the air system can be demonstrated by its effectiveness and heat recovery values. For the value of its effectiveness, according to Mostafa A.Abd El-Baky et al [9] assuming no condensation in the freshwater stream and the specific heat passing through the evaporator and condenser is constant, the equation is:

$$
\varepsilon=\frac{T_{e, \text { in }}-T_{e, o u t}}{T_{e, \text { in }}-T_{c, \text { in }}}
$$

Where Te,in is the temperature at the HPHE evaporator inlet, Te,out is the temperature at the HPHE evaporator outlet, and Tc,in is the temperature at the HPHE condensor inlet.

Temperature and relative humidity measurements were performed at 4 points using K-type thermocouples connected to NI-cDAQ 9174 and Phidgets 1125 relative humidity sensors. These 4 points are shown in Fig. 4. where point 1 at HPHE evaporator inlet, point 2 at HPHE evaporator outlet, point 3 at HPHE condensor inlet, and point 4 at HPHE condensor outlet. These measured parameters can be seen more clearly in Fig. 5. Measurements were performed on all the variations of predetermined tests. The mass flow rate of cooling coil refrigeration is set to a fixed value to reduce errors in heat recovery calculations. The Kimo AMI-300 hotwire sensor is used to measure the speed of the airflow on the ducting to match the specified value.

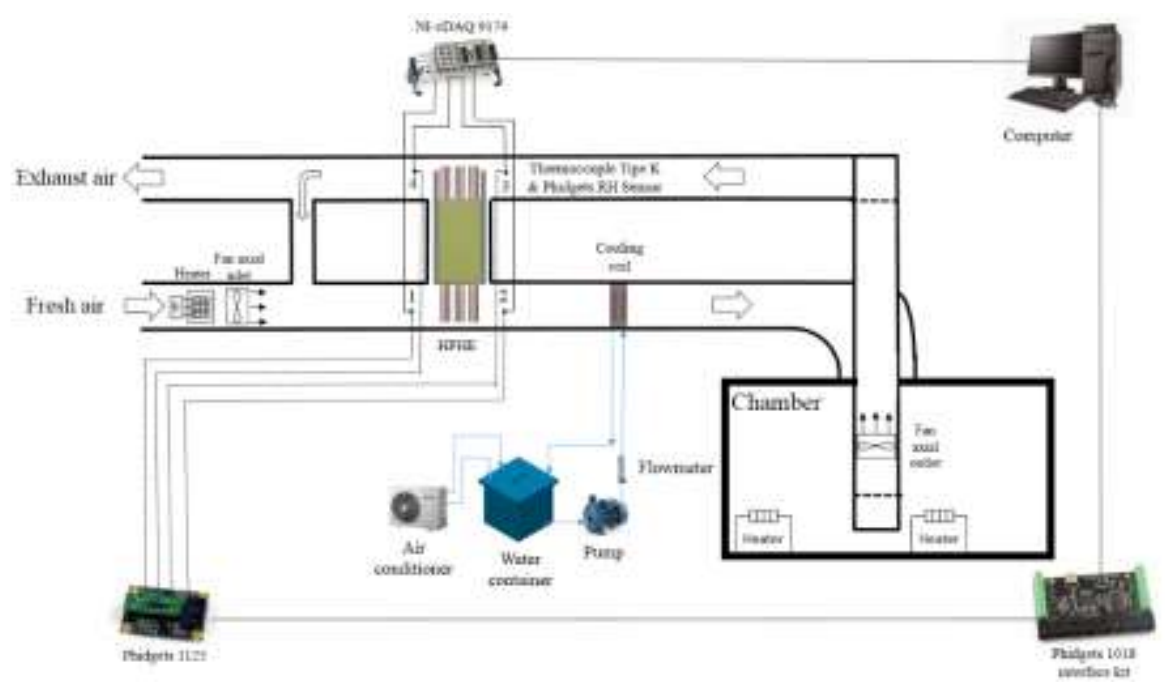

Fig. 4. Experimental setup 


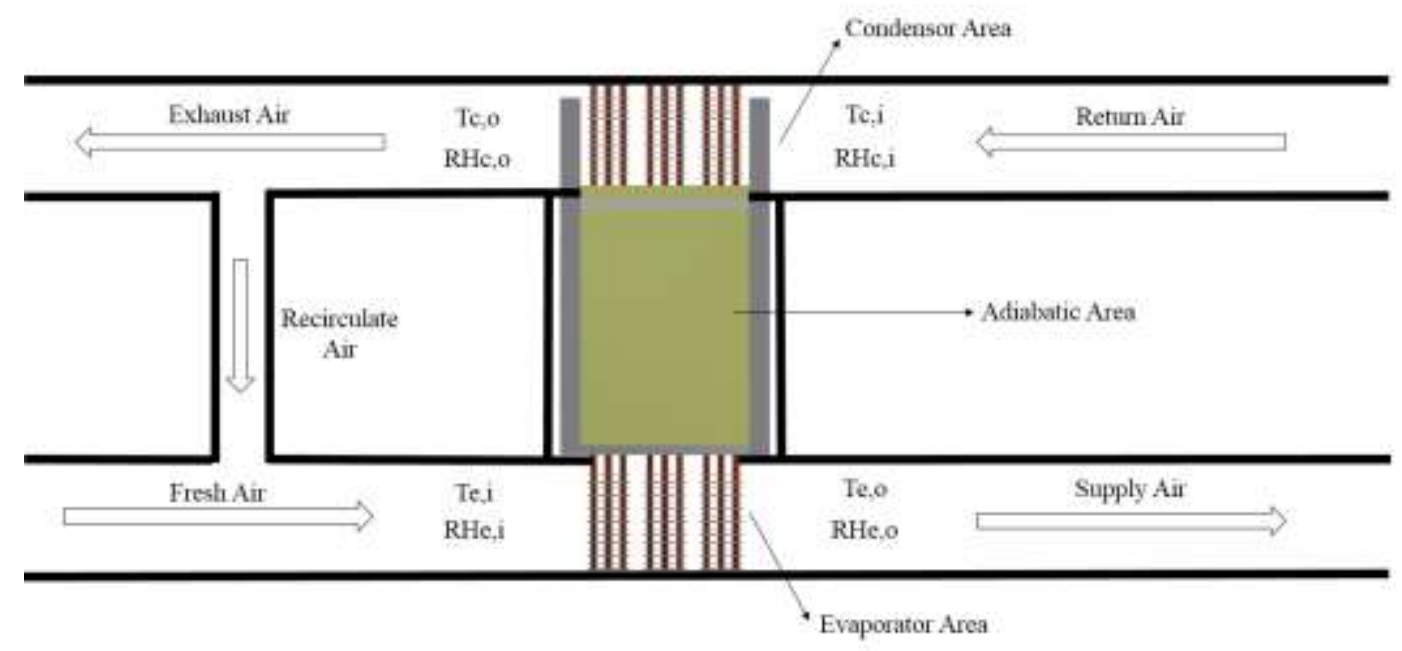

Fig. 5. Air flow and measured parameters

\section{Results and Discussion}

\subsection{Temperature and Relative Humidity Profile}

Fig. 6. Shows the temperature profiles at the HPHE evaporator inlet, HPHE evaporator outlet, HPHE condenser inlet, and HPHE condenser outlet. The graph is resulted from experiment with Te, $\mathrm{i}=40^{\circ} \mathrm{C}, \mathrm{Ve}, \mathrm{i}=1.5$ $\mathrm{m} / \mathrm{s}$ and using 3 modules. From the graph it can be seen that HPHE can decrease incoming air temperature, seen at the value of Te,o which is smaller than the value of Te,i. The HPHE evaporator absorbed the sensible heat in the air resulting in a decrease of air temperature by $5.432^{\circ} \mathrm{C}$. From this result, it can be seen that HPHE has done its function as precooling. This precooling event makes HPHE one of the tools that can be used to reduce cooling load from cooling coil. In the HPHE condenser there is an increase in air temperature, it is seen in the value of Tc,o greater than the value of Te,i. This event is caused by the release of the heat absorbed by the HPHE in the evaporator into the air passing through the condenser. In this test, the temperature change in the condenser was $2.32{ }^{\circ} \mathrm{C}$.

Fig. 7. shows the relative humidity profiles at four points of measurement. From this graph it can be seen that the relative humidity of air as it passes through the HPHE evaporator has increased from $23.98 \%$ to $32.93 \%$. This increase in relative humidity is due to a decrease in water vapor saturation pressure due to a decrease in temperature on the evaporator. While on the HPHE condenser parts, the relative humidity value decreases as the air receives the heat from the condenser section. Increased air temperatures will increase the vapor saturation pressure as well, thereby ultimately lowering the relative humidity value. The relative humidity decline in the condenser occurred from $50.81 \%$ to $46.02 \%$.

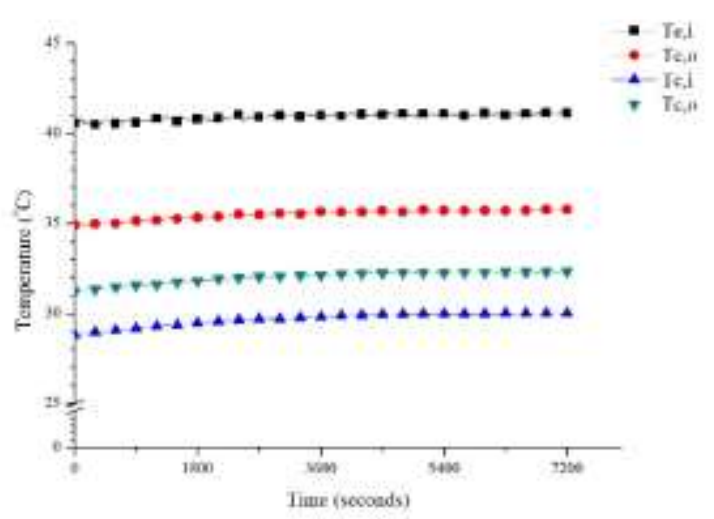

Fig. 6. Temperature profile at $\mathrm{Te}, \mathrm{i}=40{ }^{\circ} \mathrm{C}, \mathrm{Ve}, \mathrm{i}=1.5 \mathrm{~m} / \mathrm{s}, 3$ modul

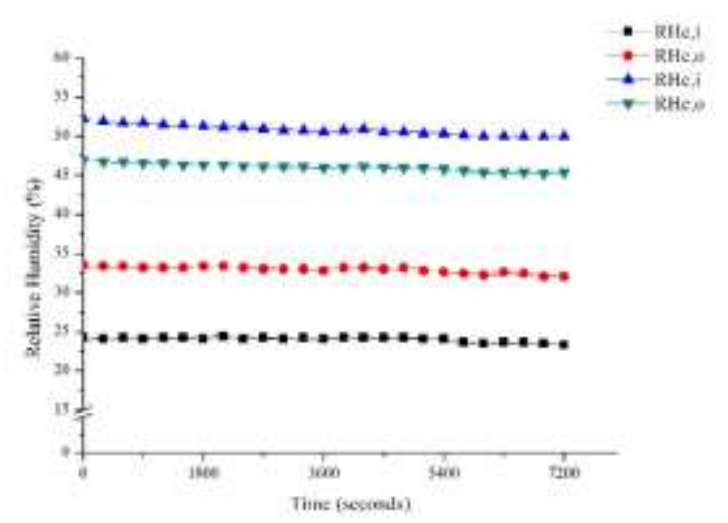

Fig. 7. Relative humidity profile at $\mathrm{Te}, \mathrm{i}=40^{\circ} \mathrm{C}, \mathrm{Ve}, \mathrm{i}=1.5$ $\mathrm{m} / \mathrm{s}, 3$ moduls 


\subsection{Effect of Inlet Air Temperature and Velocity}

Fig. 8. shows the HPHE effectiveness profile using 3 modules relative to the temperature of the inlet air of the evaporator $(\mathrm{Te}, \mathrm{i})$ and the air velocity of the evaporator $(\mathrm{Ve}, \mathrm{i})$. On the graph it can be seen that the greater the value of Te,i then the effectiveness of the HPHE tends to increase as well. But the decrease in effectiveness can also be seen with this increase in Te,i. This can happen because the value of $T e, i$ that cannot be set exactly the same for each experiment, so there is an error in the calculation. In addition, ambient temperatures can also affect the change from $T e, o$ to $T c, i$. In this graph, the effect of difference Ve,i to HPHE effectiveness is also been shown. The smaller the value of Ve,i, the greater the value of HPHE effectiveness. This is because the air contact time with HPHE becomes progressively longer which will ultimately maximize the heat transfer that occurs between these two mediums. Tests with $\mathrm{Ve}, \mathrm{i}=$ $2.0 \mathrm{~m} / \mathrm{s}$ and $2.5 \mathrm{~m} / \mathrm{s}$ have the same effectiveness change characteristics as the change of $\mathrm{Te}, \mathrm{i}$, but these characteristics differ on the test with Ve,i $1.5 \mathrm{~m} / \mathrm{s}$. This could be due to an incorrect installation error of one of the modules so that the configuration differs between tests. Further research can explain the effect of this configuration difference on the value of the effectiveness obtained.

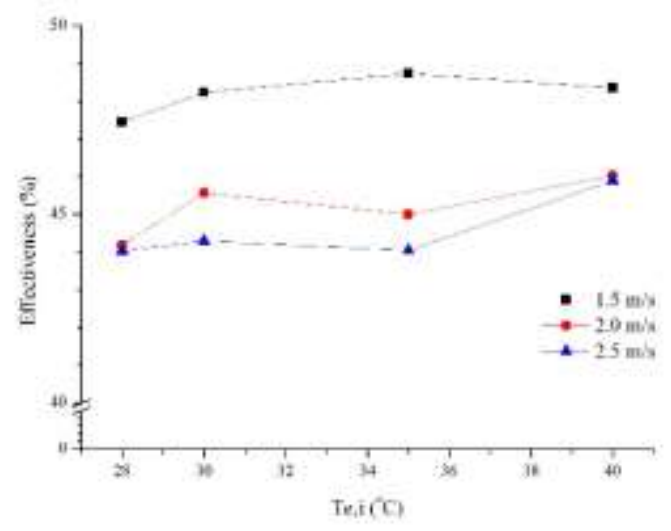

Fig. 8. HPHE effectiveness profile with 3 modules relative to $\mathrm{Ve}, \mathrm{i}$ and $\mathrm{Te}, \mathrm{i}$

Fig. 9. shows the heat recovery profile in the test with 3 modules relative to $\mathrm{Ve}, \mathrm{i}$ and Te,i. Heat recovery is a $\mathrm{Q}$ actual obtained from calculations $\mathrm{Q}_{\mathrm{act}}=$ $\dot{\mathrm{m}}_{\mathrm{h}} \mathrm{C}_{\mathrm{ph}}(\mathrm{Te}$, in $-\mathrm{Te}$, out $)$. The larger the $\mathrm{Te}, \mathrm{i}$ then heat recovery will also be greater, this is because the heat absorbed by HPHE will also be greater. The greater the $\mathrm{Ve}, \mathrm{i}$, heat recovery will be greater because although the contact time is smaller, the temperature difference on the HPHE evaporator inlet for each experiment is smaller than the increase in Ve,i. Based on the formula then the resulting heat recovery will be greater. The greatest heat recovery in the 3-module test was obtained when $\mathrm{Te}, \mathrm{i}=$
$40{ }^{\circ} \mathrm{C}$ and $\mathrm{Ve}, \mathrm{i}=2.5 \mathrm{~m} / \mathrm{s}$ of $459.645 \mathrm{~W}$ or 1654.720 $\mathrm{J} / \mathrm{kg} . \mathrm{K}$.

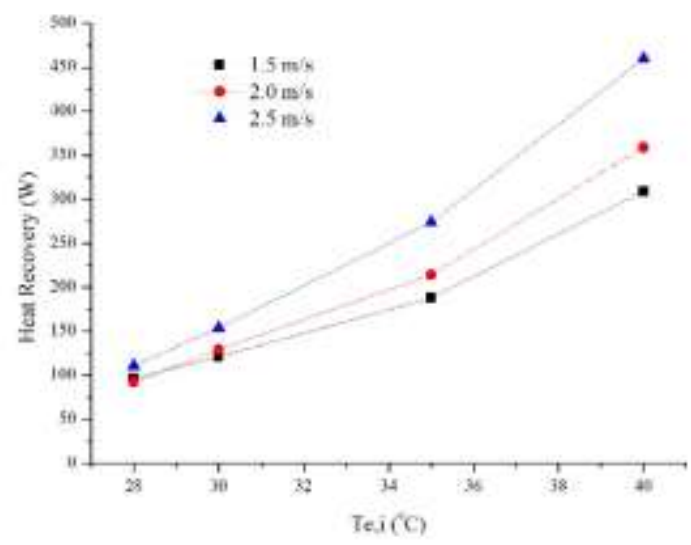

Fig. 9. HPHE heat recovery profile with 3 modules relative to $\mathrm{Ve}, \mathrm{i}$ and $\mathrm{Te}, \mathrm{i}$

\subsection{HPHE Performance}

\subsubsection{Effectiveness and Heat Recovery}

Based on the 36 variations of testing that have been done, the greatest HPHE effectiveness occurred in testing 3-modules with $\mathrm{Te}, \mathrm{i}=35^{\circ} \mathrm{C}$ and $\mathrm{Ve}, \mathrm{i}=1.5 \mathrm{~m} / \mathrm{s}$, while the smallest HPHE effectiveness occurred in the 1 -module test with $\mathrm{Te}, \mathrm{i}=35^{\circ} \mathrm{C}$ and $\mathrm{Ve}, \mathrm{i}=2.5 \mathrm{~m} / \mathrm{s}$. Table 1. shows all value of HPHE effectiveness based on the varations. The more heat pipe modules used, HPHE capacity to move the heat becomes larger. The greater the air velocity of the inlet evaporator, the contact time between the air and HPHE becomes shorter, so small air velocity will result in greater HPHE effectiveness. Increasing the inlet air temperature of the evaporator will increase the effectiveness of HPHE due to the amount of more sensible heat to be absorbed by HPHE.

In addition to the reasons mentioned above, there is one other factor that is also very influential is the compactness of the heat pipe heat exchanger itself. Based on the calculations performed, the compactness for the use of one module is $106.57 \mathrm{~m}^{2} / \mathrm{m}^{3}$, for the use of two modules valued at $213.14 \mathrm{~m}^{2} / \mathrm{m}^{3}$, and for the use of three modules valued at $319.71 \mathrm{~m}^{2} / \mathrm{m}^{3}$. The greater the compactness value means the greater the heat transfer surface area of the heat exchanger. A larger surface area with the use of three modules leads to greater HPHE effectiveness.

Table 2. shows all value of HPHE heat recovery based on the variations. The highest heat recovery occurred in the 3-modules test with Te, $\mathrm{i}=40^{\circ} \mathrm{C}$ and Ve, $\mathrm{i}$ $=2.5 \mathrm{~m} / \mathrm{s}$, and the smallest heat recovery occurred in the 1-module test with $\mathrm{Te}, \mathrm{i}=28^{\circ} \mathrm{C}$ and $\mathrm{Ve}, \mathrm{i}=1.5 \mathrm{~m} / \mathrm{s}$. This characteristic is consistent with the results of a study conducted by Nandy Putra et al [10]. In this study, the largest heat recovery value is $1654.72 \mathrm{~kJ} /$ hour. 
Table 1. Effectiveness of HPHE

\begin{tabular}{|c|c|c|c|c|c|c|c|c|c|}
\hline \multirow{2}{*}{ Te,i $\left({ }^{\circ} \mathrm{C}\right)$} & \multicolumn{3}{|c|}{ Effectiveness $(\%)$} \\
\cline { 2 - 11 } & $1.5 \mathrm{~m} / \mathrm{s}$ & $2 \mathrm{~m} / \mathrm{s}$ & $2.5 \mathrm{~m} / \mathrm{s}$ & $1.5 \mathrm{~m} / \mathrm{s}$ & $2 \mathrm{~m} / \mathrm{s}$ & $2.5 \mathrm{~m} / \mathrm{s}$ & $1.5 \mathrm{~m} / \mathrm{s}$ & $2 \mathrm{~m} / \mathrm{s}$ & $2.5 \mathrm{~m} / \mathrm{s}$ \\
\hline & 47.443 & 44.185 & 44.030 & 41.098 & 39.361 & 38.384 & 36.003 & 34.776 & 34.483 \\
\hline 28 & 48.233 & 45.566 & 44.299 & 41.143 & 38.790 & 37.664 & 35.425 & 33.682 & 33.312 \\
\hline 30 & 48.729 & 44.995 & 44.048 & 40.839 & 40.226 & 38.397 & 35.264 & 33.379 & 32.416 \\
\hline 35 & 48.344 & 46.024 & 45.890 & 41.642 & 39.710 & 38.538 & 35.071 & 33.843 & 33.075 \\
\hline
\end{tabular}

Table 2. Heat Recovery of HPHE

\begin{tabular}{|c|c|c|c|c|c|c|c|c|c|}
\hline \multirow{3}{*}{$\mathrm{Te}, \mathrm{i}\left({ }^{\circ} \mathrm{C}\right)$} & \multicolumn{9}{|c|}{ Heat Recovery (W) } \\
\hline & \multicolumn{3}{|c|}{3 modules } & \multicolumn{3}{|c|}{2 modules } & \multicolumn{3}{|c|}{1 module } \\
\hline & $1.5 \mathrm{~m} / \mathrm{s}$ & $2 \mathrm{~m} / \mathrm{s}$ & $2.5 \mathrm{~m} / \mathrm{s}$ & $1.5 \mathrm{~m} / \mathrm{s}$ & $2 \mathrm{~m} / \mathrm{s}$ & $2.5 \mathrm{~m} / \mathrm{s}$ & $1.5 \mathrm{~m} / \mathrm{s}$ & $2 \mathrm{~m} / \mathrm{s}$ & $2.5 \mathrm{~m} / \mathrm{s}$ \\
\hline 28 & 96.104 & 92.278 & 110.550 & 56.893 & 74.886 & 93.164 & 50.602 & 72.670 & 97.856 \\
\hline 30 & 121.205 & 129.353 & 154.074 & 98.531 & 130.467 & 171.131 & 70.994 & 96.041 & 126.790 \\
\hline 35 & 187.639 & 214.142 & 273.956 & 166.551 & 208.424 & 221.093 & 132.243 & 167.433 & 206.900 \\
\hline 40 & 308.785 & 358.891 & 459.645 & 259.536 & 308.103 & 350.306 & 188.772 & 247.576 & 312.008 \\
\hline
\end{tabular}

\subsubsection{Temperature Differential at Evaporator}

Fig. 10. shows the difference in air temperature before passing through the evaporator and after passing it $(\Delta \mathrm{Te}$ $=\mathrm{Te}, \mathrm{i}-\mathrm{Te}, \mathrm{o})$. It can be seen that the number of modules used in testing will increase $\Delta \mathrm{Te}$. Based on equation (1), increasing $\Delta$ Te will also increase HPHE's effectiveness, as well as its heat recovery. The larger Te,i will enlarge $\Delta \mathrm{Te}$ as more heat can be absorbed by the HPHE evaporator. The largest $\Delta \mathrm{Te}$ occurred in the 3-module test with $\mathrm{Te}, \mathrm{i}=40{ }^{\circ} \mathrm{C}$ and $\mathrm{Ve}, \mathrm{i}=1.5 \mathrm{~m} / \mathrm{s}$, while the smallest in the test 1 -module with Te, $\mathrm{i}=28^{\circ} \mathrm{C}$ and Ve, $\mathrm{i}$ $=1.5 \mathrm{~m} / \mathrm{s}$.

\subsubsection{Relative Humidity Characteristics}

Fig. 11. shows the relative humidity profiles referring to the HPHE evaporator inlet temperature. The average relative humidity in the room/ambient is approximately $50 \%$ include in the graph to find out how much change occurs when the experimental tool is run. In all variations of Te, $i, \mathrm{RHe}, \mathrm{i}$ fall lower than $50 \%$ except at a temperature of $28{ }^{\circ} \mathrm{C}$. RHe,o is always greater than $\mathrm{RHe}, \mathrm{i}$ in all variations of Te, $\mathrm{i}$ because the air decreases the vapor saturation pressure when it passes through the
HPHE evaporator. This process is called sensible precooling process by the evaporator. The change from $\mathrm{RHe}, \mathrm{o}$ to RHc, i is caused because the air temperature is lowered by cooling coil. Then RHc,o is smaller than RHc, $\mathrm{i}$ due to the addition of heat by the HPHE condenser into the air. The addition of this heat causes the addition of temperature and ultimately increases the vapor saturation pressure.

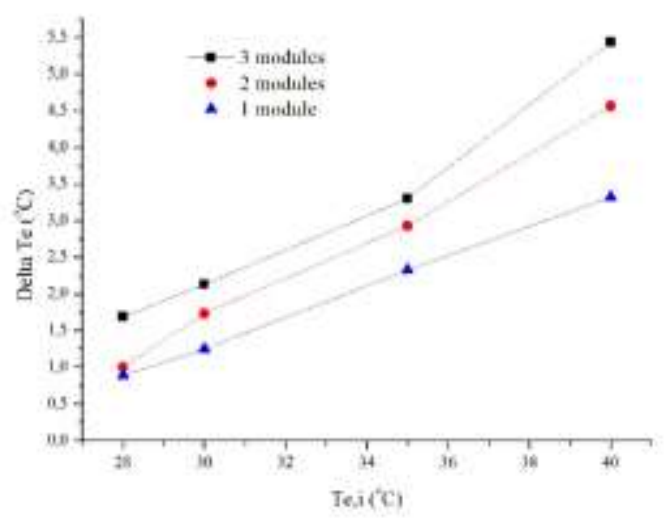

Fig. 10. $\triangle \mathrm{T}$ HPHE evaporator profile with $\mathrm{Ve}, \mathrm{i}=1.5 \mathrm{~m} / \mathrm{s}$ relative to the number of modules and Te,i 


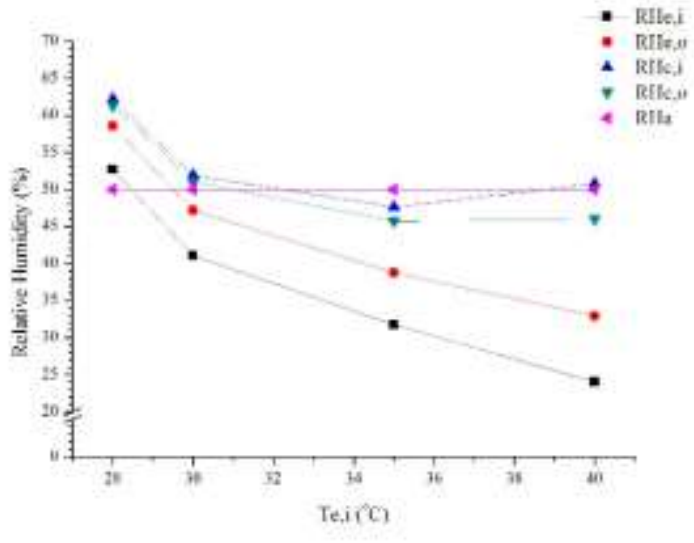

Fig. 11. Relative humidity profile with 3 modules and $\mathrm{Ve}, \mathrm{i}=$ $1.5 \mathrm{~m} / \mathrm{s}$ relative to $\mathrm{Te}, \mathrm{i}$

\subsection{Analysis of experimental data on hospital needs standard}

The ducting schematic performed on this experiment attempted to adjust to standard conditions in the hospital. In the previous study, there was only one ducting outlet above the chamber, while the present study used two ducting outlets on the right and left side of the chamber. The airflow velocity passing through these outlets is adjusted to the calculations made for positive pressurization conditions to be achieved. This is one of the factors for clean room to conform to ASHRAE standards. However, because the axial fan capacity of the outlet purchased is too high, then this condition is difficult to achieve. Setting up using a voltage regulator cannot decrease fan speed to the point where positive pressurization can be achieved. The solution to this problem is to replace the 5 inches axial outlet fan with 4 inches for both sides of the ducting outlet. With a smaller size then the fan capacity is also getting smaller so the speed can be reduced. With the offset between air velocities in and out the chamber, where air velocity is greater, positive pressurization condition can be achieved.

Under ASHRAE standards, the optimum operating room temperature is between $20-24^{\circ} \mathrm{C}$. On this research, this condition is achieved only when the air intake temperature is equal to 28 and $30^{\circ} \mathrm{C}$. When the inlet air temperature is worth 35 and $40{ }^{\circ} \mathrm{C}$, the temperature inside the chamber is between $26-29^{\circ} \mathrm{C}$. In order for this temperature value to drop and conform to the ASHRAE standard, the water flowrate acting as cooling coil refrigerant shall be changed. In this experiment, the flow rate is fixed for all test variations with a value of 4 LPM. For hospitals in Indonesia, this system can be used because weather conditions in Indonesia itself are not too hot as in extreme areas like Saudi Arabia or Egypt. Daily ambient temperatures in Indonesia range from 28$32{ }^{\circ} \mathrm{C}$, this value is obtained based on monitoring when the experiment is running.
The use of HPHE in this experiment can save energy consumption in hospitals up to $459.645 \mathrm{~W}$ or 1654.72 $\mathrm{kJ} / \mathrm{hr}$. This savings can occur under optimal conditions with 3 modules, $\mathrm{Te}, \mathrm{i}=40^{\circ} \mathrm{C}$, and $\mathrm{Ve}, \mathrm{i}=2.5 \mathrm{~m} / \mathrm{s}$. For real conditions, where $\mathrm{Te}, \mathrm{i}$ is smaller than that, the saving that can be done is between 100-300 W. Energy saving efforts at the hospital are also analyzed and taken into account in the research of M. Ahmadzadehtalatapeh et al [11] and A. Teke et al [12].

\section{Conclusion}

From this research, the HPHE effectiveness value increases with the increasing of the number of modules and the amount of air temperature inlet evaporator but decreases as the airspeed increases. The HPHE Heat Recovery Value increases with the increasing of the number of modules, the amount of air temperature inlet evaporator, and the air velocity. The greatest HPHE effectiveness is $48.729 \%$, it was obtained when using three modules, air temperature inlet evaporator $(\mathrm{Te}, \mathrm{i})=$ $35^{\circ} \mathrm{C}$, and air speed of inlet $1.5 \mathrm{~m} / \mathrm{s}$. The smallest HPHE effectiveness is $32.416 \%$ when using one module, air temperature inlet evaporator $(\mathrm{Te}, \mathrm{i})=35{ }^{\circ} \mathrm{C}$, and air speed inlet $2.5 \mathrm{~m} / \mathrm{s}$. The largest heat recovery is 459.645 $\mathrm{W}$ or $1654.72 \mathrm{~kJ} / \mathrm{h}$, obtained when using three modules, air temperature inlet evaporator $(\mathrm{Te}, \mathrm{i})=40^{\circ} \mathrm{C}$, and air speed inlet $2.5 \mathrm{~m} / \mathrm{s}$. The smallest heat recovery is 50.602 $\mathrm{W}$ or $182.169 \mathrm{~kJ} / \mathrm{h}$, obtained when using one module, air temperature inlet evaporator $(\mathrm{Te}, \mathrm{i})=28{ }^{\circ} \mathrm{C}$, and air speed of inlet $1.5 \mathrm{~m} / \mathrm{s}$. The thermal comfort conditions (temperature and relative humidity) for $\mathrm{Te}, \mathrm{i}=28{ }^{\circ} \mathrm{C}$ and $30^{\circ} \mathrm{C}$ has fulfilled ASHRAE standard.

The author would like to thank Directorate of Research and Community Engagements Universitas Indonesia (DRPM UI) and Kemenristek Dikti for funding this research through the PITTA 2018 scheme with contract number 2452/UN2.R3.1/HKP.5.00/2018 and PPUPT scheme respectively and also Mr. Iwan Chandra, CEO of PT. Aicool Indonesia for manufacturing the HPHE module.

\section{References}

1. Law of the Republic of Indonesia Number 44 Year 2009 About Hospital

2. ASHRAE, HVAC Design Manual for Hospitals and Clinics, Second Edition: p. 28, (2013)

3. B2TE-BPPT, Energy Efficiency and Elasticity Planning 2012, Jakarta: BPPT Press, (2012)

4. Srimuang, W. and P. Amatachaya, A review of the applications of heat pipe heat exchangers for heat recovery, Renewable and Sustainable Energy Reviews, 16 (6): p. 4303-4315, (2012)

5. Putra, N.S.D., T. Anggoro, A. Winarta, Experimental Study of Heat Pipe Heat Exchangers in Hospital HVAC System for Energy Conservation, International Journal on Advanced 
Science, Engineering and Information Technology, 7 (3), (2017)

6. Yau, Y.H., The use of a double heat pipe heat exchanger system for reducing energy consumption of treating ventilation water in an operating theater-A full year energy consumption model simulation, Energy and Buildings, 40 (5): p.917-925, (2008)

7. Wang, H., et al., A study of secondary heat recovery efficiency of heat pipe heat exchanger air conditioning system, Energy and Building, 133: p. 206-216, (2016)

8. Govinda Mahajan, H.C., Scott M Thomson, Harrison Rupp, Kevin Muse, Oscillating Heat Pipe For Waste Heat Recovery in HVAC System, ASME 2015, Proceeding of ASME 2015 International Mechanical Engineering Congress and Exposition, (2015)

9. Abd El-Baky, M.A. and M.M. Mohamed, Heat pipe heat exchanger for heat recovery in air conditioning, Applied Thermal Engineering, 27 (4): p. 795-801, (2007)

10. Muhammaddiyah, S., A. Winarta, N. Putra, Experimental Study Of Multi-fin Heat Pipe Heat Exchanger For Energy Efficiency In Operating Room Air Systems, International Journal of Technology, 2: 422-429, (2018)

11. Ahmadzadehtalatapeh, M., Yau, Y.H., The application of heat pipe heat exchangers to improve the air quality and reduce the energy consumption of the air conditioning systems in a hospital ward-a full year model simulation, Energy and Buildings, 43 (9):2344-2355, (2011)

12. Teke, A., Timur, O., Assessing the energy efficiency improvement potentials of HVAC systems considering economic and environmental aspects at the hospitals, Renew. Sustain. Energy Rev, 7, 3282-3303, (2014) 